\title{
Miraculous Healing and Long-Term Medical Remission of Systemic Lupus Erythematosus (SLE) - The Role of Divinity Within the Future of Medicine
}

\author{
Richard Sarnat* \\ Chief Medical Officer, Advanced Medicine Integration Group, USA
}

Submission: March 13, 2019; Published: May 15, 2019

*Corresponding author: Richard Sarnat, Chief Medical Officer, Advanced Medicine Integration Group, USA

\begin{abstract}
While "miraculous healings" or spontaneous remissions of various disease states have been scientifically reported previously, the exact mechanism, which allow for these seeming miracles or spontaneous remissions is poorly understood. By contrast, I have recently published multiple case studies, which have included the "miraculous healings" of Sarcoidosis, Chronic Lyme Disease, Fibromyalgia, Parkinson's disease, severe chronic debilitating plantar arthritis and metastatic squamous cell carcinoma without the use of pharmaceuticals or antibiotics and where the mechanism of action used to initiate the "miraculous healing" appears to have a cause and effect relationship and thus is reproducible.

This case report now adds Systemic Lupus Erythematosus (SLE) (case study \#6) to the previous five case studies, which I have observed and now report to be successfully treated by a process, which Master John Douglas refers to as "Angelic Reformation." These case reports are representative of the many hundreds of case studies I have documented (although most yet unpublished) over a ten-year period, while observing the work of Master John Douglas and the graduates of his Elite Development course. While certainly inspiring, admittedly all of these observations must ultimately be subjected to additional rigorous scientific methodology. Yet, the sheer number of miraculous healings I have observed and the fact that this body of knowledge can be taught to others who obtain similarly effective results is very promising, given our current confusion regarding the exact mechanisms of action and/or causation of autoimmune diseases.
\end{abstract}

Keywords: Systemic lupus erythematosus; Miraculous healing; Master john douglas; Angelic reformation

Abbrevations: SLE: Systemic Lupus Erythematosus; TCM: Traditional Chinese Medicine

\section{Introduction}

The ancient philosophers and theologians have been debating the existence of the Soul since time immemorial. University students studying academic philosophy become well versed in the various historical arguments for the "Proof" of God and/or the "Proof" of the Soul. However, with the study of past life regressions and their suggested potential impact on present medical conditions, I would assert that this previously philosophical/theological inquiry has now fallen within the prevue of science [1].

Furthermore, with the recent inclusion of consciousnessbased modalities as a covered benefit into our health care system, such as meditation, yoga, Tai Chi and Reiki, we are now approaching the junction point where science and spirituality must meet and reckon with each other. Since the infamous split of mind and body by Rene Descartes, this moment of reckoning has been gathering momentum, heralded by the paradigm shift to mind/body medicine we are now witnessing. But I believe that this is only the first step of reconciling the truth of how our universe is constructed and understanding the nature and design of our place (as human beings) within the Whole. Many consciousness-based modalities, such as yoga, meditation, tai chi and energy medicine all aim to correct an imbalance that exists as the root cause of a given patient's disease state. The fundamentals of Ayur-Veda and Traditional Chinese Medicine (TCM) attempt to restore proper balance to a physiology struggling with a world filled with environmental toxins, non-nutritious food, impure water and the sensory overload typical of the new millennia. But at their deepest healing level, these traditional medical systems reconnect the patient with their Divine Self, with their God, by teaching consciousness-based, self-improvement techniques which allow the patient to transcend beyond the human construction of their intellect, mind and emotions. This is the ultimate goal of yoga and meditation - to provide true a priori knowledge of the Divine Self and its primacy in the universe. 
This is the fundamental experience which is the "aha moment" and lays the foundation for lasting self-correction and/or even miraculous healing to occur.

World history has recorded the seeming miraculous healings ascribed to many different saints and healers but while "miraculous healings" or spontaneous medical remissions of various disease states have been scientifically reported previously, the exact mechanism, which allow for these seeming miracles or medical remissions is poorly understood. By contrast, I have recently published in multiple peer-reviewed and indexed medical journals a series of case studies, which have included the "miraculous healings" of Sarcoidosis, Chronic Lyme Disease, Fibromyalgia, Parkinson's disease, Severe Chronic Debilitating Plantar Arthritis and Metastatic Squamous Cell Carcinoma without the use of pharmaceuticals or antibiotics and where the mechanism of action used to initiate the "miraculous healing" appears to have a cause and effect relationship and thus is reproducible [2-5].

This case report now adds Systemic Lupus Erythematosus (case study \#7) to the previous six case studies, which I have observed and now report to be successfully treated by a process, which Master John Douglas, an Australian energy healer, refers to as "Angelic Reformation." These case reports are representative of the many hundreds of case studies I have documented (although most yet unpublished) over a ten-year period, while observing the work of Master John Douglas and the graduates of his Elite Development course. While certainly inspiring, admittedly all these observations must ultimately be subjected to additional rigorous scientific methodology. Yet, the sheer number of miraculous healings I have observed and the fact that this body of knowledge can be taught to others who obtain similarly effective results is very promising, given our current confusion regarding the exact mechanisms of action and/or causation of autoimmune diseases, dementias and many other chronic disease states.

While not a conspiracy theorist by nature, I cannot help but notice the existing bias in our research paradigms and research funding, which seems to ignore the many tell-tale signs that many idiopathic and autoimmune diseases are probably caused by an underlying unknown infectious etiology. One cannot help but notice the resemblance of this mindset to the pre-existing bias before the recent scientific discoveries that many cancers and duodenal ulcers have an infectious etiology as their root-cause. My own recent publications, which assert this same hypothesis, are derived from my observations of Master John Douglas, and his ability to clairvoyantly identify the infectious root causes of many "idiopathic" diseases. Recently many universitybased scientists have asserted this same infectious hypothesis underlying chronic diseases, based on extensive evidence gained in the nonclinical basic science laboratories, which lay the foundations of our current pathophysiological model [6]. The publication of this case study on SLE is yet another addition to the evidence base that an underlying infectious etiology is the probable root cause of many of our idiopathic and autoimmune diseases.

\section{Case Study \#7 (Cs \#7)}

a. Systemic Lupus Erythematosus (Sle)

CS \#7 is a 40-year-old white female who first met Master John Douglas, a well-known Australian energy healer, in 2007 at a public seminar in Ojai, California while she was in "good health". By 2009 her "good health" status had changed, and she was diagnosed with very early stage Systemic Lupus Erythematosus based on her lab work and constellation of classic clinical signs and symptoms.

She reports that her medical doctor said, "her disease process was incurable; the same physician introduced her to a support group of other Lupus patients, so she would be reality based about her future." Dismayed by the attitude of this physician, she never returned for follow-up. She has no significant past medical, social or family history. She was not using recreational drugs, alcohol or taking any pharmaceuticals at the time of her diagnosis. She describes her 2009 symptoms as, "severe pain inside my bones as if my bones were frozen. The pain was a constant 9/10 daily. I had a very low energy level and a constant undiagnosed flu-like syndrome with generalized muscle aches."

Formerly a professional dancer, she now required a hot bath first thing in the morning just to be able to move at all. Dancing was out of the question. Attempting to find an alternative cure, she tried hyperbaric oxygen chambers, intravenous oxygen infusion, acupuncture and homeopathy. None of these modalities stopped her disease progression or offered her permanent relief. Her symptoms continued to become progressively worse until 2010, when she again saw Master John Douglas for a personal healing session in Santa Barbara. As soon as she saw him, she reports that, "I had a complete shift in my well- being overall; I knew I would be cured." By the time she left the session, she "experienced a 100\% improvement in her symptoms."

However, Master John Douglas warned her that, "her disease would not be fully healed until he could work on a deeper level." This turned out to be true, as she experienced a slow relapse to about $20 \%$ - $30 \%$ of her former symptoms in the timeframe between seeing him again at future seminars. She did, however, attempt to go to every seminar he gave within the state of California, which amounted to seeing him 6 - 8 times annually. During this early phase of her recovery, she also reports using tourmaline detoxification foot patches daily, taking detoxification Epsom salt and sea salt baths 3-4 times weekly and using micronutrient mineral supplementation, all at the suggestion of Master John Douglas to help her body detoxify. Her more permanent and complete miraculous healing occurred when Master John Douglas released a new audio guided-meditation process called "Soul Repair". Once Master John Douglas, as he 
reports, "was literally able to effect a healing at the Soul level," and she was able to listen to the audio CD "Soul Repair" daily, her recovery became $100 \%$ stable, without any recurrence of symptoms. She, to this day, is still able to resume all of her former activities, even dancing.

\section{Discussion}

As I have recently reported elsewhere [2-5], Master John Douglas uses his clairvoyant senses to identify the infectious etiology and root cause of many idiopathic diseases. Although the infectious agents for these idiopathic diseases have not been discovered or reported in the scientific literature, he claims "to be able to directly visualize the existence of hundreds of unknown infectious agents through his enhanced (clairvoyant) senses, no different than we observe ordinary phenomena in the material world, such as the leaves on trees."

The credibility of this assertion is supported by the fact that annually, open to the public, he teaches hundreds of students to replicate his findings at a seminar called the Elite Development Course. To date, over 500 people have been trained to detect these hidden infectious agents by a method called "scanning", which enables the observer, phenomenologically, on the level of consciousness, to measure the unique electromagnetic wave signal emanating from each unique infectious agent, analogous to the way each element of the periodic table has a corresponding unique molecular weight.

Granted, most of these infectious agents have yet to be identified by virologists, microbiologists, parasitologists or any conventional medical apparatus. And while the inability to verify the existence of these infectious agents apart from consensus among Elite Course graduates is disruptive to our conventional medical paradigm, is this claim all that different from saying that prior to an electron microscope, many minute infectious agents were not seen with an ordinary light microscope or that the essential elements of quantum physics which were mathematically deduced could not be proven without the technological advancement which allowed for the building a linear particle accelerator? While admittedly this technology is consciousness-based and does not exist as an external device currently, philosophically I believe that there is no barrier to replicating these findings using an external device as technology advances.

Historically there was a time in the not too distant past where the idea of an infectious agent as the root cause of cancer would have been heretical. Yet now we know that in the developing world nearly $20 \%$ of all cancers are secondary manifestations of disease due to earlier antecedent infections, such as hepatitis $B$, hepatitis $C$ and human papillomavirus infection [6,7]. Similar to my other previously reported case studies of "auto-immune" diseases, I believe that (SLE) always has an underlying infectious etiology. The human physiology is simply too well designed and engineered to attack itself erroneously, without provocation.
Master John Douglas asserts that, "Lupus is caused by a mould, coupled with a coexistent symbiotic bacterium, which then eats the mould and the duo together deposit their toxins in any organ, such as kidney, liver or spleen. Killing the mould results in a cure."

Yet in the early phase of her healing before the development of the Soul Repair audio CD, while her symptoms and quality of life improved, a complete and stable miraculous healing was not achieved. This fact gives us, I believe, a glimpse into the deeper laws of nature that govern true miraculous healing - the laws of karma, which I believe are multi-dimensional, and that interact with more subtle energetic levels of creation which transcend our earthly physical body. If this paradigm of multi-dimensional healing is true, then this case report adds further evidence to the already reported case studies involving past life regressions and the idea that both our physical and subtle energy bodies have an almost infinite complexity and are connected by interdimensional portals to other time/space continuums where residual pathology can reside, which must be dealt with for "true healing" to occur. Given this paradigm of inter-dimensional pathology and healing, it is interesting to note that until Master John Douglas was able to eradicate the mould/bacteria on that most fundamental quantum energy level, which he termed "the level of the Soul”, complete miraculous healing was not achieved.

\section{Study Limitations}

Admittedly, this case report has many limitations. While a licensed medical doctor, who was confident in her diagnosis, established the original diagnosis, there are no corresponding lab tests, videos or even a second opinion to corroborate the diagnosis. Even the role of the placebo effect must be considered as a variable triggering the self-reported transformation, which was subjectively experienced in the presence of Master John Douglas. I also realize that as "scanning" is a consciousnessbased technique, not common to the public at large, and only mastered by graduates of the Elite Development Course as taught by Master John Douglas, this limits the population of "experts" capable of confirming or refuting the accuracy of this report to under 500 current graduates. So it is entirely reasonable to question a "miraculous cure" that rests entirely on the resolution of symptoms as reported by the patient, except for the fact that 500 people are independently capable of measuring the presence of the frequency of an infectious agent and/or cancer cell signals which is killed by conscious intention and then observe that the resolution of symptoms is closely correlated in time with the disappearance of that infectious agent's electromagnetic signal (as measured by the process of "scanning").

\section{Conclusion}

Notwithstanding the obvious limitations of the study as listed above, I still believe that the sheer number of seeming "miraculous healings" which I have witnessed over a ten year period and the fact that this ability can be taught and reproduced 
by many licensed health professionals forces us to consider the possibility that an infectious cause and effect relationship exists as the underlying mechanism of the "miraculous healings" which have been reported.

Furthermore, given the published evidence of other research scientists at major medical institutions, it calls into question why additional funding is not being focused on this hypothesis. It seems prudent, therefore, for all non-pharmaceutical and non-surgical options such as the technology described herein to be further investigated, whenever the credible probability of their improved therapeutic benefit is known. Our goal as physicians is always to use the treatment option with the best therapeutic ratio, and thus minimize any iatrogenic component to our delivery of care. And while I realize that we are a long way off from having a solid scientific foundation to recommend the technology described herein, not to further investigate the reality of these observations in a more rigorous setting would be a mistake in my opinion [8].

\section{References}

1. Newton Michael (1994) Case Studies of Life Between Lives Journey of Souls Llewellyn Publications, Woodbury, Minnesota
2. Sarnat R (2018) Miraculous Healings of Chronic Lyme disease, Fibromyalgia and Sarcoidosis without the Use of Pharmaceuticals or Antibiotics. OBM Integrative and Complementary Medicine 3(1): 003.

3. Sarnat RL (2018) Miraculous Healing of Parkinson's disease Without the Use of Pharmaceuticals, Antibiotics or Surgery. Advances in Complementary \& Alternative Medicine 3(2).

4. Sarnat RL (2018) Miraculous healing of Severe Chronic Debilitating Plantar Arthropathy Without the use of Surgery or Pharmaceuticals. ACTA Scientific Orthopaedics 1(3): 23-27.

5. Richard L S (2018) Miraculous Healing of Metastatic Squamous Cell Carcinoma - The Role of Adjunctive Energy Healing. J Complement Med Alt Healthcare 8(4): 555-745.

6. Itzhaki, Ruth F, Lathe, Richard, Balin, Brian J (2016) Microbes and Alzheimer's Disease. J Alzheimers Dis 51(4): 979-84.

7. Plummer M, de Martel C, Vignat J, Ferlay J, Bray F, Franceschi S (2016) Global burden of cancers attributable to infections in 2012: a synthetic analysis. Lancet Glob Health 4(9): e609-16.

8. Jonas WB, Cindy Crawford, Luana C, Ted J Kaptchuk, Bruce Moseley, et al. (2015) "To what extent are surgery and invasive procedures effective beyond placebo response? A systematic review with metaanalysis of randomized, sham controlled trials". Surgery Research 5(12): e009655.

Your next submission with Juniper Publishers will reach you the below assets

- Quality Editorial service

- Swift Peer Review

- Reprints availability

- E-prints Service

- Manuscript Podcast for convenient understanding

- Global attainment for your research

- Manuscript accessibility in different formats

( Pdf, E-pub, Full Text, Audio)

- Unceasing customer service

Track the below URL for one-step submission

https://juniperpublishers.com/online-submission.php 